\title{
0 game levado a sério: o sujeito lúdico em Arlindo Machado Video games taken
} seriously: the ludic subject in Arlindo Machado

Gilson Schwartz ${ }^{1}$ 
Resumo: A obra de Arlindo Machado questiona de modo pioneiro o automatismo da sociedade do espetáculo e suas ideias abrem-se para o diálogo com as novas formas de produção e consumo da imagem, assim como para o modo de ser do olhar. Apesar de não figurar entre os autores mais citados no campo dos jogos eletrônicos ou game studies, a trajetória de Machado revela-se certeira e pioneira na identificação dos limites e potenciais dos automatismos audiovisuais. Assim como os casos do cinema, do documentário e do vídeo, o game é levado a sério nessa obra crítica propícia às reinvenções criativas que redefinem os horizontes do olhar para a sociedade do espetáculo audiovisual.

Palavras-chave: videogames; pós-cinema; semiótica; tecnologia; audiovisual.

\begin{abstract}
The legacy of Arlindo Machado pioneered in questioning the automatism of the society of the spectacle, with his ideas opening space for a dialogue with new forms of production and consumption of images, as well as for the existential mode of the human gaze. Although excluded from the array of most cited authors in game studies, the intellectual path of Machado proves to be an accurate and pioneering reference in identifying the limits and potentials of audiovisual automatisms. As films, documentaries, or videos, this critical work takes games seriously, being prone to creative reinventions that redefine visibility in the society of the audiovisual spectacle.
\end{abstract}

Keywords: videogames; post-cinema; semiotics; technology; audiovisual. 


\section{Subjetividades pós-cartesianas}

Arlindo Machado não chegou a se debruçar extensivamente sobre o universo dos videogames. Em seu Lattes (com última atualização em 31 de março de 2020), há apenas uma orientação sobre o tema dentre 43 teses de doutorado (GOMES, 2008). Obviamente isso não revela muito sobre a intensidade, a densidade e a relevância de sua obra para pensar os games. Ao contrário, serve de estímulo às novas gerações que, sem acesso à sua pessoa na Pontifícia Universidade Católica de São Paulo (PUC-SP) ou na Universidade de São Paulo (USP), já ousam projetar no universo dos games o mesmo apelo ao tratamento sério que ele soube convocar provocativamente para o vídeo, a TV, o pós-cinema e seu próprio olhar.

Mas se Arlindo fez pouco pelos game studies, ele não fez por menos chegou a rebatizar uma orientanda como Renata "Games", que aventurou-se no game Alice (um jogo lançado em 2000, para PC Windows e Mac OS), teve sua tese Agentes Verossímeis defendida em Comunicação e Semiótica pela PUC-SP (um estudo sobre game, narrativa e construção de personagens autônomos) e foi agraciada com a Menção Honrosa no Prêmio Capes de Teses 2008 na área de Ciências Sociais Aplicadas, além de ter sido a única premiada da área de Comunicação.

"Arlindíssima” desde o Mestrado (também na PUC-SP, em que produziu a dissertação Imersão $\nleftarrow$ Participação, sobre game, narrativa e Umwelt, também sob a orientação de Arlindo Machado), Renata "Games”, em seu depoimento no podcast Dazumana, informa que ao buscar nos games o sentido da narrativa, ela compartilha com seu orientador a referência a Janet Murray, que em Hamlet no Holodeck: $\mathrm{O}$ futuro da narrativa no ciberespaço aponta para a narrativa no ciberespaço como desafio à invenção de novas âncoras conceituais.

O Lattes de Arlindo Machado revela algumas poucas outras participações no campo dos game studies: participou das bancas de mestrado (Games 3D, Aspectos de Desenvolvimento, de 2007) e doutorado (Estados Superpostos: Proposta de Modelo Matemático para Games 3D, de 2012) de Marcos Fernandez Cuzziol (orientado por Gilbertto Prado); e orientou em 2005 o mestrado de Aleph Teruya Eichemberg (A Experiência do Tempo Morto no Cinema e nos Games, 2005, em Comunicação e Semiótica na PUC-SP). Cabe notar que seu Lattes não tem nenhuma referência a transmídia - o que não surpreende para quem foi pioneiro em pensar a arte transgênica (BRITTON, COLLINS, 2003). Machado politizava a inovação audiovisual, em vez de cultuar a técnica pela técnica, aproximando-se de Vilém Flusser e George Simondon. 
Sua influência na produção acadêmica brasileira sobre games, no entanto, é maior do que revela o próprio Lattes. Foi um apaixonado pela aceleração tecnológica e seus efeitos sobre o tempo, a subjetividade e a reinvenção artística dos meios e dos processos audiovisuais. Da análise de narrativas seriadas em suas categorias e modalidades à própria atitude de atribuir valor (ético e estético) aos produtos da indústria cultural audiovisual de massa e suas margens, brechas e potenciais disruptivos, críticos e desalienantes, Arlindo Machado tornou-se referência obrigatória nas bibliografias de muitos pesquisadores do fenômeno lúdico-digital.

A própria Janet Murray, ao tratar da transformação no paradigma narrativo associada à emergência do "ciberespaço", recorre a uma imagem derivada do cinema, ou pelo menos de um cinema que se aproxima da ciência (tema também caro a Machado, Simondon e Flusser), pautado por narrativas agonísticas estruturadas ou facilmente adaptáveis ao formato dos games (o livro de Murray é de 1997, a edição em português foi publicada em 2001 e não encara frontalmente a questão dos videogames).

O holodeck é um dispositivo derivado do holograma, fonte científica de inspiração para o gadget que se tornou um dos ícones da franquia Star Wars (que remonta aos anos 1960). Já se tratava de um dispositivo de realidade aumentada ou realidade virtual, ou seja, uma contrapartida tecnófila ou mesmo tecnicista das experiências de "consciência expandida” que movimentavam a juventude da geração “paz e amor" (em contraponto à Guerra Fria, às corridas espacial e armamentista e à proibição de guerras nucleares no espaço sideral). O método holográfico foi premiado com o Nobel de Física em 1971, recebido por seu inventor, Dennis Gabor, um judeu húngaro que combateu na I Guerra Mundial e dedicou-se ao estudo das propriedades das correntes elétricas de alta voltagem, técnica que levaria ao microscópio eletrônico e às televisões de tubos catódicos e telas de plasma energizadas por frequências de rádio. Nota-se a coincidência com o interesse de Arlindo Machado pelos processos tecnológicos associados à produção da imagem televisiva e com sua atenção à obra experimental de Nam June Paik, que interfere na operação dos tubos catódicos.

Aquela seria conhecida como a "Bienal dos videomakers", em que a obra TV Garden (1974) de Paik "surpreendeu o público brasileiro ao dispor monitores em meio a uma vegetação de palmeiras em vasos e plantas artificiais" na $13^{\mathrm{a}}$ Bienal de São Paulo, em 1975. 


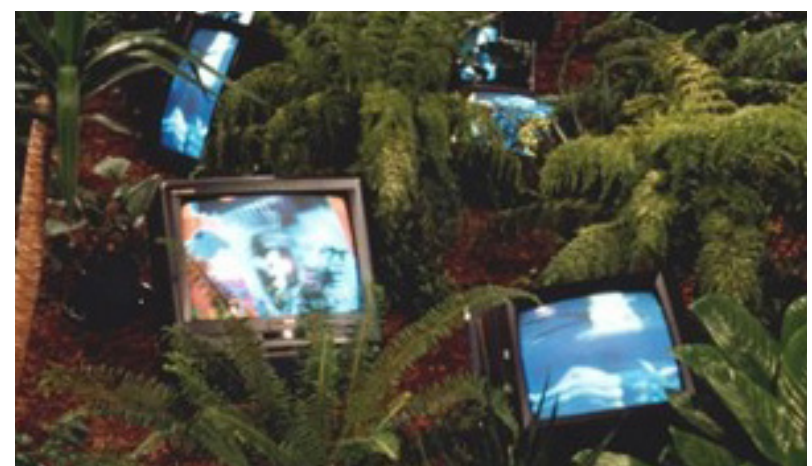

Figura 1: TV Garden, 1974. Videoinstalação de Nam June Paik. ${ }^{2}$

Nessa mesma época, os primeiros consoles com o videogame Pong (lançado pela Atari em 1972) chegavam aos lares da alta classe média globalizada.

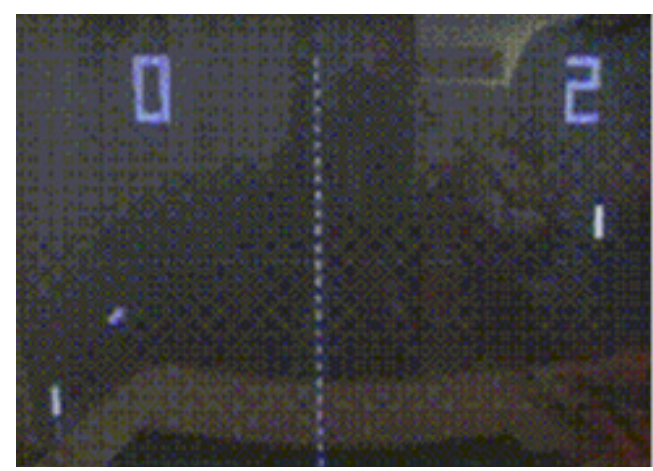

Figura 2: Tela de Pong (1972)

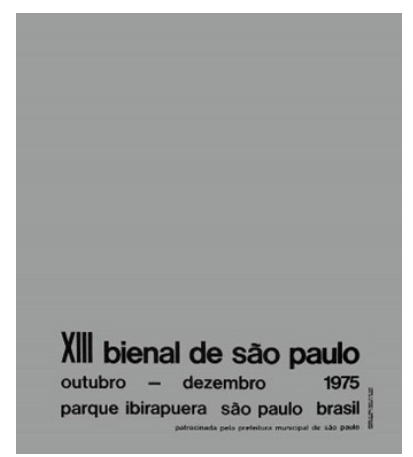

Figura 3: Cartaz da $13^{a}$ Bienal de São Paulo (1975). ${ }^{3}$

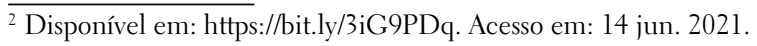

${ }^{3}$ Disponível em: http://www.bienal.org.br/exposicoes/l3bienal. Acesso em: 03 mar. 2021.
} 
Para Arlindo Machado, a experiência essencial é o contato com a "pós-TV" e sua temporalidade. A combinação de Pong com Nam June Paik era ao mesmo tempo transformadora e intensamente tecnológica e imaginativa. A imagem não representava mais, ela se punha como relação e processo de interferência sobre o significado do que se projetava na caixa preta, uma narrativa completamente dependente da capacidade do "receptor" de se colocar ativamente nos planos da imaginação e de um agenciamento inédito.

Tanto na tela de Pong (Figura 2) quanto no cartaz da Bienal (Figura 3), há um convite ao preenchimento - com o olhar, a atenção, o corpo e a mente - de uma tela que se apresenta em duas cores, em uma mistura de espelho com buraco negro. O cartaz criado por Rogério Batagliese e Maria Elisabeth S. Nogueira já foi dissecado como uma "grande folha de papel metalizado, limpa, faz as vezes de espelho para o espectador mirar-se” (BIENAL 50 ANOS, 2001, p. 298).

Trata-se de "uma peça gráfica aberta a múltiplas leituras: pode ser entendida como tradução do novo momento cultural, no qual os limites entre o que é e o que não é arte são cada vez mais difíceis de definir; ou como mensagem de que a natureza última da arte é refletir o mundo que a envolve; ou ainda como alusão à situação política do país, na qual não restam mais alternativas de discurso a não ser refletir o real em sua dimensão mais concreta e imediata” (Bienal 50 Anos, 1951-2001, p. 298 apud http://www.bienal.org.br/exposicoes/13bienal/cartazes/4239).

É também o fim do "Milagre" que se aproxima, a experiência democrática que se reanima, a crise do petróleo que se anuncia, assim como o desbunde, o mergulho na psicodelia e a consolidação da indústria cultural amparada no crédito ao consumidor e na dívida mundial.

O vídeo é um game, o game é um vídeo. De um lado, a publicidade se apropriava rapidamente de todas essas linguagens e técnicas, definindo o tempo da TV em dólares por segundo. De outro, a crise da representação se armava aceleradamente por meio de dispositivos técnicos e novas caixas-pretas que ampliavam praticamente ao infinito os desafios postos desde o final do século XIX aos pensadores da imagem, sobretudo da fotografia, terreno primordial dos estudos de Arlindo Machado, disposto a mostrar a carga de afetos, desejos e angústias indissociáveis das máquinas semióticas e dos agenciamentos audiovisuais.

Da fotografia ao vídeo, do vídeo ao... videogame? Hoje talvez Arlindo Machado publicasse um livro com o título "o game levado a sério".

Já em 2001, Arlindo Machado resumia pouco mais de uma década de pesquisas após a publicação de A Arte do Vídeo, uma rememoração dos anos 1980 , 
quando "a questão da enunciação constituiu um dos temas que mais mobilizou a teoria cinematográfica” (MACHADO, 2001, p. 1). E prossegue informando que o declínio dessa vertente teórica teve início no começo dos anos 1990 e foi “o resultado de uma incapacidade dos primeiros teorizadores em encarar o cinema como um meio híbrido e, de outro, pelo fato do próprio cinema começar a transformar-se a partir da hegemonia da televisão e do surgimento dos novos meios” (MACHADO, 2001, p. 1).

O objetivo de Machado seria, então, "verificar o que deve mudar na teoria da enunciação a partir da consideração das novas formas de produzir e consumir mensagens audiovisuais introduzidas pelos meios eletrônicos e digitais" (MACHADO, 2001, p. 1). E menciona os videogames ao se declarar interessado em "retomar as técnicas de imersão, experimentadas em espetáculos pré-cinematográficos, como os panoramas do século 19" para verificar "como elas são retomadas nos atuais videogames e nos dispositivos de realidade virtual" (MACHADO, 2001, p. 1).

Estava ele em sintonia não só com Janet Murray, mas também com Brenda Laurel (1991) e Allucquère Rosanne Stone (1996), que tratam das narrativas interativas e do fenômeno que "os povos de língua inglesa" chamam de agenciamento ou "agency", ou seja, "o efeito de assujeitamento do espectador necessário à ilusão de imersão” (MACHADO, 2001, p. 1).

Subjetivação e assujeitamento são uma via de mão dupla em que a própria noção de autor será diluída em redes de aparatos produtores de imagens técnicas que não estarão alinhadas necessariamente à democracia, à emancipação ou à criatividade.

Trata-se, em suma, de definir um horizonte de pesquisa sobre as “imagens técnicas" (expressão consagrada na obra de Vilém Flusser) em que são instaurados "novos regimes de subjetividade" (tema que ganharia força na retomada da obra de Gilbert Simondon sobre “individuação”). O arsenal teórico de Arlindo Machado no início dos anos 2000 já aponta para a questão da relação entre vídeo (e arte) em mecanismos cada vez mais sofisticados de imersão e assujeitamento.

Além da reflexão de Janet Murray “sobre os mecanismos de imersão e os modos como o leitor/espectador interage com as situações potenciais acumuladas nas memórias de computador" (MACHADO, 2001, p. 1), seria necessário convocar as ideias de Sherry Turkle sobre "as personalidades virtuais (avatares) que habitam o chamado ciberespaço e o desenvolvimento de identidades múltiplas nas situações de interação mediadas por computadores" (MACHADO, 2001, p. 4).

Em 2001, Arlindo Machado "estava ligado" na emergência dos games. Já transitava do holodeck e dos hologramas para os hologames. O locus do chamado 
"fascínio hipnótico" do cinema deslocava-se para outras telas, situadas em ambientes domésticos ou novos espaços de entretenimento (basta lembrar da era das lan-houses), e a experiência audiovisual passa a ser determinada pela serialização e pela fragmentação, de forma que "o próprio espectador, com seu controle remoto, introduz uma nova descontinuidade através da prática do zapping” (MACHADO, 2001, p. 3).

Tecnicamente, o controle remoto está muito próximo do "ame controller" praticamente o ícone essencial da era lúdica (que inicialmente exigia apenas o uso das duas mãos e passou a abarcar cada vez mais participação de todo o corpo, até chegar ao movimento da cabeça e do próprio globo ocular nos capacetes de imersão 3D).

A tela do cinema é transparente, enquanto a tela do vídeo (e, portanto, do videogame) é opaca, pequena, estilhaçada, sem profundidade, pouco "realista" e de “precário poder ilusionista” como já notara o próprio Arlindo Machado em 1988 em seu “A Arte do Vídeo”. É o que ostentam analogicamente as telas de Pong (Figura 2) e o cartaz da Bienal (Figura 3).

O trabalho de enfeitiçamento acontece em outros lugares, envolve outras relações e agenciamentos, outros tempos e ritmos ("flows") e uma gigantesca máquina publicitária que supostamente coloca o corpo de cada jogador no "controle" da experiência audiovisual.

Portanto, não é casual que "os novos meios que surgiram depois do cinema não estimularam reflexões relacionadas ao modo como a subjetividade é neles construída e, por consequência, uma teoria da enunciação pós-cinematográfica não foi jamais formulada, pelo menos não de forma tão sistemática como o foi na literatura e no cinema" (MACHADO, 2001, p. 3).

\section{Imagens técnicas e o jogo da individuação aurática na iconomia}

Arlindo Machado jamais cessou de questionar a centralidade do aparato técnico na formulação dessa necessária nova "teoria da enunciação" na esfera digital. Suas investigações perpassam de Walter Benjamin a Janet Murray e Jean-François Lyotard, de forma que o espaço e o tempo, assim como as doses de técnica, de feitiço e de agenciamento associadas à operação de um mundo de comportamentos, ideias e circulações financeiras determinadas por imagens técnicas, passam a depender de uma nova formulação em que o "regime de subjetivação" ou as "novas figuras da subjetividade" sejam dissecadas em primeiro plano, à procura de uma anatomia do ser humano em redes digitais.

Assim, ele passa a buscar uma nova ética e estética para a era eletrônica. Afinal, "o suporte instrumental parece resumir o aspecto mais simples do problema" 
(MACHADO, 2002a, p. 20), enquanto o desafio artístico maior é desviar a tecnologia de seu projeto industrial.

Benjaminiano interessado numa dialética positiva, Machado propõe que sejam usadas as próprias máquinas semióticas para superar nossa condição de "funcionários" (termo de Vilém Flusser) e adentrar uma reinvenção da aura no ponto de fuga extremo da arte na época de sua reprodutibilidade técnica.

Nos anos 2000, sua pesquisa mergulharia definitivamente no destrinchar desses novos tipos de sujeito/sujeição, agenciamento e multiplicação identitária, já que os "regimes de imersão" e os "modos de agenciamento" ampliaram as modalidades de imersão do sujeito nas imagens.

O mundo é dinamicamente alterado pela nossa participação, já que há uma negociação em curso a cada contato com as imagens técnicas. Portanto, a caixa-preta sou eu.

A relação entre representação e interação/interagente tornou-se mais fluida, porosa, fragmentada e complexa, condicionada pela natureza simbólica do avatar ou pela perspectiva escolhida para a câmera que nos revela o metaverso digital.

Estaria a poética aristotélica ainda a operar nos videogames? Seria o jogo apenas uma forma especializada de dramaturgia ainda condicionada pelas estratégias narrativas clássicas? O fato é que não existe mais uma única maneira de fazer evoluir a narrativa num jogo. Haverá sempre lugares e até mesmo personagens que seguirão desconhecidos depois que o interagente chega ao final de um videogame. Não há via de mão única num universo lúdico.

A novidade está numa "hipérbole do sujeito": uma espécie de "narcisismo radical e autorreferenciado, em que a única identificação possível é a do sujeito com ele mesmo" (MACHADO, 2002b, p. 6), ainda que o uso de máscaras seja um recurso ampliado ao infinito da carnavalização. Mikhail Bakhtin é mobilizado no âmbito de sua teoria da composição de identidades múltiplas, de forma que a observação do mundo dos computadores atualiza a teoria da máscara carnavalesca, representada pelo avatar que cumpre um papel "mais propriamente psicanalítico do que político: ela exprime uma crise de identidades que não tomou ainda a forma de uma crítica dos costumes, mas que se dissimula em projeções e metáforas de natureza freudiana" (MACHADO, 2002b, p. 11). Essa relação entre máscara, interface e digitalização midiática é, portanto, uma perspectiva de Machado bastante apropriada para uma dimensão crítica do game design, que envolve a construção de personagens e avatares e a manipulação da subjetividade criada tecnicamente pela câmera encenadora de cada nível de um jogo. 
Para Bakhtin, a máscara tem "um sentido político e desmistificador na cultura carnavalesca, permitindo jogar um olhar divergente sobre o mundo, um olhar ainda não enquadrado pelo cabresto da civilização, de modo a tornar sensível a relatividade dos valores e a circunstancialidade dos poderes e saberes" (MACHADO, 2002b, p. 11).

No entanto, no mundo dos computadores, a máscara representada pelo avatar "cumpre um papel mais propriamente psicanalítico do que político: ela exprime uma crise de identidades que não tomou ainda a forma de uma crítica dos costumes, mas que se dissimula em projeções e metáforas de natureza freudiana" (MACHADO, 2002b, p. 11). Trata-se de um horizonte interpretativo pertinente numa sociedade em que a interface substitui o espelho e milhões de crianças e adolescentes formam suas identidades projetando-se nas configurações lúdicas póshumanas centradas na difusão das caixas-pretas digitais, perspectiva adotada também por Manfred Fassler (2000).

Arlindo Machado, desde seu interesse (ainda nos anos 1970) pelo filmeensaio, pela obra de Eisenstein e, em última análise, pela relação entre pensamento e imagem em movimento, busca uma nova teoria do pós-sujeito que se define em meio às metamorfoses da imagem técnica.

O potencial de "desvio" do "projeto industrial" na sociedade do espetáculo está no agenciamento possibilitado pelo jogo aberto na fragmentação das identidades cujo horizonte emancipatório depende de processos sociais, políticos e semióticos.

As pistas estão na retomada por Arlindo Machado dos olhares de Flusser e Simondon, já iluminadoras de uma perspectiva tão reclamada de uma nova teoria da enunciação derivada das operações técnicas plasmadas nos ciclos da imagem e da imaginação.

Essa necessária economia da individuação audiovisual é pelo menos sugerida em textos de Arlindo Machado que lidam mais diretamente com o olhar e o imperativo de desprogramação das máquinas semióticas. Nessa perspectiva, ele segue na contramão do que afirmam algumas leituras de sua obra, como Feitosa (2008), que assinala que “é bom que se diga, o autor trabalha na perspectiva do cinema como uma espécie de referência fundadora de todo o audiovisual, inclusive no ciberespaço" (p. 3).

Foi explícita a necessidade, formulada pelo próprio Arlindo Machado, de uma nova teoria da enunciação, ou seja, o reconhecimento da crise fundamental que impede a teoria do cinema de alcançar a nova era eletrônica. Machado vai além do cinema e da TV e cobra que se amplie ou mesmo abandone a proposta teórica ancorada na história do cinema e seu pensamento. É preciso levar rigorosa e literalmente a necessidade de um pós-cinema. É preciso levar o game a sério. 
Mas como adentrar os game controllers, os consoles, as caixas-pretas da interação lúdica (do X-Box aos capacetes da gamificação 3D) para reencontrar a aura criativa que a campanha de vida de Arlindo Machado propugnava contra a submissão da arte ao tempo da publicidade e ao assujeitamento funcional das identidades aos projetos de hegemonia alienante da indústria cultural? Ou seja, como aproximar de modo efetivo a era eletrônica de novas ética, estética e técnica com horizontes autenticamente democráticos e emancipatórios?

O deslocamento proposto por Arlindo Machado como condição para superar a era do cinema exige uma crítica mais ampla do tecnocentrismo e uma nova teoria da subjetivação mediada por imagens e por imaginação como processos abertos a releituras, desconstruções e interferências análogas à produzida por Nam June Paik sobre o tubo catódico da TV.

Vilém Flusser figura como referência fundamental nessa busca desde 1997, quando Machado apresenta Repensando Flusser e as Imagens Técnicas no evento Arte en la Era Electrónica: Perspectivas de una nueva estética, realizado em Barcelona, no Centre de Cultura Contemporania, de 29 de janeiro a 01 de fevereiro, sob a organização de Claudia Giannetti e promoção do Goethe-Institut de Barcelona (MACHADO, 1997a). Nesse mesmo texto, aparece a referência à obra então conhecida de Gilbert Simondon, Du mode d'existence des objets téchnique (1969). O ponto de partida de Machado é o "nível de competência tecnológica" exigido dos artistas contemporâneos que se aventuram "com dispositivos ou processos tecnológicos" (p. 7). Ou seja, o foco é deslocado da experiência imersiva do consumidor/interator para o espaço-tempo de produção da experiência estética e das implicações éticas da rendição ao império da tecnologia.

São reverberações mais "germânicas", são texturas heideggerianas, é uma fenomenologia em que a relação entre técnica, linguagem e humanismo ganha o primeiro plano, território claramente abordado com centralidade na obra de Vilém Flusser. É uma nova anatomia da relação entre corpo, imagem e pensamento que remete aos destinos trágicos da técnica nos estertores da mitologia iluminista.

A caixa-preta a partir da qual não há mais associação possível entre obra de arte e aura seria ainda o horizonte possível de uma criatividade, de um imaginário capaz de se libertar da programação algorítmica implícita à produção das imagens técnicas? Pode o artista que lida com tecnologia superar a condição de funcionário da grande indústria do espetáculo cultural?

Arlindo Machado se prepara (e nos prepara) para um debate que vai muito além do cinema, notadamente num momento em que o game torna-se princípio 
de organização imagética da esfera pública e a vida privada torna-se palco trágico da gamificação programada no tempo, no espaço e nas emoções, condicionando o próprio pensamento, a política e as possibilidades de socialização, emprego e saúde.

Percebe-se que Machado trilhava caminhos teóricos já distantes das questões metodológicas e mesmo puramente pragmáticas da produção cultural para atacar “problemas filosóficos importantes e estratégicos para se definir o estatuto da arte nas sociedades industriais ou pós-industriais” (MACHADO, 1997a, p. 2).

\section{O jogo da liberdade sem medo}

Para Machado, "uma das formulações mais agudas desse problema foi realizada por Vilém Flusser". Trata desse importante pensador tcheco como alguém "que viveu 31 anos no Brasil, tendo sido o principal mentor intelectual de várias gerações de artistas brasileiros que enfrentaram o desafio da tecnologia" (MACHADO, 1997a, p. 2).

Machado refere-se, então, à Filosofia da Caixa Preta como uma "reflexão densa sobre as possibilidades de criação e liberdade numa sociedade cada vez mais centralizada pela tecnologia". No final dos anos 90, logo após a morte de Flusser, Machado reitera que ele "permanece ainda, nos círculos que discutem a arte da era eletrônica, um pensador pouco conhecido, mas cuja contribuição fundamental nesse campo demanda resgate urgente" (MACHADO, 1997a, p. 2).

Esse resgate exige efetivamente a competência para realizar uma nova forma de “codificação icônica”. Trata-se, portanto, in nuce, de um convite a resgatar Flusser como pensamento fundante da capacidade de socialização imagética de determinados conceitos científicos, na medida em que a produção audiovisual é indissociável de operações matemáticas e algoritmos, de que os jogos eletrônicos são um dos exemplos mais acabados.

Flusser, como Machado, percebe o potencial do game design como uma competência altamente prática/técnica ou metodológica, mas também como novo modo de enunciação e negociação das relações e de operações da imaginação que conecta cada indivíduo a seu próprio mundo. Tanto Flusser quanto Machado abordam fenômenos e processos associados à evolução da imagem técnica e das “caixas-pretas" com as quais são produzidos, mas ainda deixaram uma fonte a ser explorada quando se trata de compreender melhor o game design.

Um game design com perspectiva flusseriano-machadiana tem como horizonte criativo as representações icônicas mediadas por aparelhos. Já não se trata, assim, nem de duplicação inocente do mundo (porque entre elas e o mundo 
se interpõem transdutores abstratos, os conceitos da formalização científica que informam o funcionamento de máquinas semióticas como a câmera fotográfica e o computador), nem de completamente abrir mão da hipótese de intervenção criativa nas máquinas e em seus sistemas de conexão distribuída por meio de infraestruturas tangíveis e superestruturas intangíveis. Portanto, uma máquina semiótica condensa em suas formas materiais e imateriais um certo número de potencialidades.

A liberdade e a criatividade são possíveis porque cada imagem técnica produzida através de uma máquina semiótica representa a realização de algumas dessas possibilidades. Contudo, por definição, essa realização não esgota o universo de possibilidades técnicas, materiais e imateriais, posto que tais máquinas podem operar apenas como processos, em redes que poderão tornar-se mais ou menos flexíveis e abertas. Nenhum banco de dados abolirá o acaso, a história e a ética.

Ora, máquinas e programas são "criações da inteligência do homem”, são "materializações de um processo mental", "pensamento que tomou corpo". Basta desafiar o poder de repetição dessas máquinas e softwares, recusar a "repetição indiscriminada" que conduz inevitavelmente à estereotipia, ou seja, à homogeneidade e previsibilidade dos resultados, evitando "a multiplicação à nossa volta de modelos pré-fabricados, generalizados pelo software comercial” (MACHADO, 1997a, p. 4).

A proposta de game design de Machado a partir de Flusser é clara: se "é natural e até mesmo desejável que uma máquina de lavar roupas repita sempre e invariavelmente a mesma operação técnica, que é a de lavar roupas, não é, todavia, a mesma coisa que se espera de aparelhos destinados a intervir no imaginário, ou de máquinas semióticas cuja função básica é produzir bens simbólicos destinados à inteligência e à sensibilidade do homem” (MACHADO, 1997a, p. 2).

Resta-nos a “insurgência contra essa automação estúpida”, contra a robotização da consciência e da sensibilidade para "recolocar as questões da liberdade e da criatividade no contexto de uma sociedade cada vez mais informatizada e cada vez mais dependente da tecnologia" (MACHADO, 1997a, p. 2).

Como alcançar essa competência criativa e evitar a robotização que hoje se tornou regra nas redes sociais e até nas indústrias culturais? É preciso superar a própria hipótese (com a qual o próprio Flusser teria flertado) de possibilidades limitadas de intervenção sobre máquinas semióticas. É preciso rigorosamente encarar essas máquinas como artefatos com os quais e contra os quais armam-se jogos e pode-se reabrir negociações culturais. 
Afinal, Flusser reconhece que existem regiões "na imaginação dos aparelhos" que permanecem inexploradas, "regiões que o artista navega preferencialmente, para trazer à luz imagens nunca antes visualizadas".

Bastante fiel a essa visão de Flusser, Arlindo Machado conclui que na situação-limite, "a relação entre usuário e aparelho aparece como um jogo" (MACHADO, 1997a, p. 5). Pois Flusser “reconhece que esse jogo se dá de forma superlativamente concentrada no campo da arte de caráter experimental, onde o artista luta por desviar o aparelho de sua função programada e, por extensão, para evitar a redundância e favorecer a invenção" (MACHADO, 1997a, p. 5).

Haverá, no final da história, o predomínio do universo tecnológico que incorpora as descobertas e os desvios dos artistas para os seus fins programados? Afinal, se "toda rota nova descoberta" é acrescentada ao universo de possibilidades do(s) aparelho(s), então em última análise “as máquinas semióticas se alimentam das inquietações dos artistas experimentais e as utilizam como um mecanismo de feedback para o seu contínuo aperfeiçoamento" (MACHADO, 1997a, p. 6).

Arlindo Machado, retomando o insight da Nam June Paik (que "com a ajuda de ímãs poderosos, desvia o fluxo dos elétrons no interior do tubo iconoscópico da televisão"), afirma que o realizador não cumpre apenas “possibilidades” do meio. Ele está "atravessando os limites da máquina e reinventando radicalmente o seu programa e as suas finalidades" (MACHADO, 1997a, p. 9).

É necessário saber programar, ou seja, entrar na caixa-preta tão profundamente quanto possível, para "branqueá-la”? Sim! Mas metáforas da ordem do Espaço são de pouca valia nesse contexto. Não se trata de uma "entrada” ou uma "abertura", mas sim da integração a processos de individuação e transindividuação em que o processo técnico e a biopolítica fazem parte de operações transparentes, desejantes e criativas.

Nessa linha prosseguiu Gilbert Simondon, cujas obras apenas recentemente ganharam maior visibilidade e pertinência em numerosos campos da ciência, da arte e da política. A transindividuação é uma operação que remete ao conatus tal como examinado, por exemplo, na tradição que remonta a Spinoza, conforme sugere Marilena Chauí (2019). Aqui, é necessário retornar aos momentos pré-Iluministas da própria razão científica ou do método geométrico, possivelmente retomando insights machadianos, que falava de Eisenstein tendo como horizonte a emergência de uma geometria do êxtase.

Concluímos esta seção com Machado/Flusser: a atividade artística e crítica é fundamentalmente contraditória e lúdica. Trata-se de "repensar o próprio conceito 
de arte, absorvendo construtiva e positivamente os novos processos formativos abertos pelas máquinas”. Mas também é o caso de “tornar também sensíveis e explícitas as finalidades embutidas em grande parte dos projetos tecnológicos, sejam elas de natureza bélica, policial ou ideológica” (MACHADO, 1997a, p. 11).

A arte coloca a humanidade diante do desafio de poder viver livremente num mundo programado por aparelhos. "Apontar o caminho da liberdade" é, segundo Flusser, “a única revolução ainda possível” (MACHADO, 1997a, p. 11).

\section{Olhar o olhar: tempo, espaço e transindividuação lúdica}

A pesquisa e a reflexão de Arlindo Machado ganham sentido pleno apenas no horizonte da ludicidade audiovisual em seus desafios de reenquadramento da subjetividade, da narratividade e da própria possibilidade de superar a alienação funcional rumo à liberdade, à criatividade e à emancipação digital num contexto de transindividuação lúdica na sociedade do espetáculo.

Sua obra investigou também a pesquisa sobre a relação entre games e documentário, mais especificamente sobre o fenômeno conhecido como "machinima". Nessa vertente, novamente é levantada a questão das relações entre corpo, verdade e técnica que toma o primeiro plano, remontando à distinção espinosana derivada de uma proposta imanente de processualidade entre corpo, ação e afetividade.

Em Novos Territórios do Documentário, Machado (2011) novamente nos convida a perceber os limites das categorias tradicionais de classificação da narrativa audiovisual, jogando luz sobre as metamorfoses do gênero documentário. Como em outras obras de revisão crítica, o que se apresenta como novo território leva-nos a uma revisão radical da tradição. Possivelmente vale também para os games o que Machado afirmou sobre o documentário: trata-se de uma forma que "tem um problema básico: nós todos falamos dele, mas não sabemos bem o que ele é” (p. 2).

As várias possibilidades de alargamento, inversão ou mesmo perversão de um impossível conceito preciso do que seria um documentário não resistem nem à investigação epistemológica de seu conceito, nem à concepção ilusão de que um aparato técnico qualquer teria o dom de capturar a realidade verdadeiramente real. Nesse processo de apagamento conceitual, Machado vai em direção à animação e aos games como casos de superação das definições tradicionais de documentário.

O exemplo maior dessa convergência entre games e documentário é o gênero machinima. O primeiro filme reconhecido como machinima foi feito no jogo Quake, lançado em 1996. Machinimas também podem ser criados a partir de ambientes 
virtuais interativos em tempo real que permitam gravar a ação do jogo. Há jogos cuja finalidade é a criação de machinimas e, recentemente, os engines surgiram como resposta aos obstáculos à filmagem: são softwares de criação de jogos, que configuram uma inovação na produção audiovisual que torna a cada dia menos visível a separação entre a filmagem "real" da produção de "efeitos especiais". Machado aponta para os machinimia de fundo político.

Outro exemplo eloquente do apagamento de fronteiras de gênero impulsionadas pela gamificação é a plataforma Second Life, em que o documentarista Gabriel Mascaro passa a "viver” trabalhando como um avatar de... documentarista.

A reflexão de Arlindo Machado sobre o "fim" do documentário assume o viés de uma ampliação das condições sociais, ideológicas, estéticas e éticas em que a inovação tecnológica é apropriada por novos olhares. É a emergência do novo olhar que emerge em primeiro plano e, nesse sentido, a visada lúdica torna-se mais definidora dos rumos do audiovisual contemporâneo que a consideração estritamente técnica desta ou daquela "caixa-preta".

O tema é retomado em Máquina de Animação, texto publicado em edição especial da revista do Cinusp sobre Machinima (apud MORAN, PATROCÍNIO, 2011). Novamente, a oscilação se dá entre a importância do cinema na sobredeterminação das novas formas de criação audiovisual e a inevitável emergência de uma cultura audiovisual totalmente nova, moldada pela transformação tecnológica que, para ser criativa, exigirá um novo olhar cujas fronteiras com relação ao cinema ainda estamos tentando distinguir. É o olhar de Arlindo Machado sobre o cinema e sua evolução que demanda se queremos levar também os jogos e videogames a sério.

A observação aguda de Machado remete a uma forma de perversão da tecnologia dos videogames pelos realizadores, de forma que os games são um exemplo acabado da operação flusseriana-simondoniana de reinvenção técnica a partir de novas relações entre indivíduos, técnicas e afetos. Essa perversão dialética da técnica é indissociável da cultura, remetendo novamente ao que Simondon definiu como "transindividuação".

Ademais, não se trata simplesmente de uma nova maneira de fazer filmes (como se tudo o que há de novo em tecnologia audiovisual devesse responder ou ganhar status de inteligibilidade a partir dos comportamentos e da estética cinematográfica), pois afinal trata-se também de uma "nova forma de jogar" (MACHADO, p. 93 apud MORAN, PATROCÍNIO, 2011).

Os games tornam-se de pleno direito uma "nova possibilidade de produzir conteúdo audiovisual”. Como já fizera com o vídeo e a televisão, Arlindo 
Machado leva o game a sério. Das entranhas algorítmicas do game design, um novo agenciamento abre uma clareira no ser e no tempo da imagem técnica, muda a relação entre corpo, mente e máquina semiótica através de uma "a oportunidade de criar um novo conceito de cinematografia baseado nos games, talvez até mesmo uma nova mídia" (MACHADO, p. 93 apud MORAN, 2011).

Machado prossegue extraindo conclusões revolucionárias de cada detalhe técnico associado à produção audiovisual ancorado em ludonarrativas digitais: os vídeos machinima constituem uma "curiosa surpresa no mundo dos videogames e também uma inovação no campo do cinema, que parecia paralisado por uma certa inércia criativa" (MACHADO, p. 97 apud MORAN, 2011). A transindividuação lúdica digital associa-se a uma irrupção iconômica, há uma economia política e até sanitária nos novos procedimentos em que o valor das coisas decorre de uma relação entre imagem técnica e processos vitais de transindividuação (já não é necessário enfrentar serpentes, infartos e alimentar exércitos para filmar algo como Apocalypse Now!).

Assim, fica evidente que "uma tecnologia é definida não apenas pelos seus produtores, mas também pelos seus usuários, que podem redirecionar as suas funções através de um uso diferenciado". O mesmo ocorreu com o videoclipe e o videocassete em suas versões portáteis, que foram "desenhados originalmente como monitores para treinamento em empresas e esportes, mas acabaram se transformando em motores de uma grande revolução cultural" a partir de um "uso desviante" e "mais avançado" pela comunidade de seus usuários (MACHADO, p. 98 apud MORAN, 2011).

Há uma "negociação", uma operação aberta à criatividade, ao desvio, à perversão e à desconstrução do consumismo de massa até no interior das máquinas semióticas - e os games serviram para Arlindo Machado como exemplos perfeitos dessas teses mais amplas sobre a relação entre imagem, imaginação e técnica.

$\mathrm{O}$ olhar de Arlindo Machado sobre o cinema frente à fotografia, que combina técnica racional e iluminista que ao mesmo tempo está a serviço de um certo ofuscamento e da abertura para acessos aos fantasmas do inconsciente, reverbera em sua análise da passagem do cinema à gamificação que marca o destino contemporâneo do pós-cinema. A videoarte e os videogames são parte de uma mesma transição técnica e histórica da década de 1970, em que a Guerra Fria cede lugar a guerras virtuais, culturais e digitais.

Ao longo dos últimos anos, seus textos avançam rumo a essa nova teoria da enunciação que pressupõe uma aposta criativa na apropriação transindividual da caixa-preta a partir de uma revisão crítica do próprio olhar. Em 2019, essas pistas são 
oferecidas em A Visão sob o Enfoque Audiovisual. Abria-se para Machado uma etapa de "revisão crítica de premissas", de forma que quase 20 anos depois de seus trabalhos de revisão das teorias da enunciação e do cinema, ele dirige sua visão ao próprio Olhar, orientando-se para uma "revisão crítica das principais teorias recentes sobre a maneira como o olho interpreta o mundo" (MACHADO, 2019, p. 1).

É na visão que se opera a dupla inscrição do dentro e do fora. Se não fala em Simondon ou Flusser, retoma conceitos de inspiração biopolítica como Umwelt de Jacob Johann von Uexküll (autor do final do século XIX), que são relevantes na obra dos filósofos da protensão criativa e aberta. Eles colocam a técnica que se traduz em próteses audiovisuais no contexto vivo da conexão entre imagem e imaginação, em que a observação implica interações entre o observador e o sistema observado. Novamente a ciência, a biologia e a cultura são unidas numa visão relacional, processual e aberta ao desvio frente à programação industrial e alienante que faz de Arlindo Machado uma leitura essencial ao universo dos games entendidos como fronteira mais avançada do capitalismo audiovisual ou dos ícones digitais.

Como em Espinosa, para Arlindo Machado o próprio olho pensa, e corpos e sistemas cognitivos definem-se historicamente como campos criativos tão abertos quanto um jogo que se situa a cada momento na fronteira entre regras, programação e artifícios e o êxtase, o desejo e a fantasia. Não se pode pensar a mente como puramente racional e instrumental. Como na situação lúdica, cada indivíduo pensa com seus sentidos até no processo de interatuação com outros, reais ou virtuais, programados ou não. No olhar de Arlindo, o corpo todo é um ser pensante e o próprio olhar pode estar nos dedos, sensíveis o suficiente tanto para viabilizar a leitura do código braile, quanto para mergulhar em formas cada vez mais complexas de "controlar" a experiência lúdica digital ou híbrida, com capacetes ou chips implantados no corpo.

Em todo jogo, assim como em Flusser e Simondon, já não faz sentido perder-se nos labirintos da subjetividade. Nas reflexões finais de Arlindo Machado, a busca pela subjetivação emancipatória remete à ideia básica da "unidade complementar" de sujeito e objeto, sem subjetivismo ou objetivismo em benefício de uma compreensão da visão como um processo que articula operações incertas entre corpos, mentes e sistemas de comunicação.

É nessa dimensão transindividual do sujeito lúdico que se projetam as possibilidades desviantes das futuras máquinas-corpos semióticos. O olhar de Arlindo Machado coloca as telas futuras a serviço da liberdade de corpos, mentes e desejos.

Esse olhar exige uma leitura nas entrelinhas de seus textos e um exame cuidadoso de suas referências, sobretudo pelo gradual, sutil e documentado, 
deslocamento de sua perspectiva ao longo dos anos, seja em termos de objeto (fotografia, cinema, TV, pós-TV e games e quase-performances), seja em termos de referências filosóficas (das referências mais anglo-saxãs para uma orientação mais continental e germânica, acompanhando a "guinada afetiva" da filosofia contemporânea como em Simondon).

O deslocamento na obra de Arlindo Machado teve como horizonte a superação do foco em meios, suportes e processos audiovisuais para mirar a conversão do próprio audiovisual (quando se desloca da narrativa ou da enunciação para o próprio olhar) em índice de um estilhaçamento político, social, ético e estético da individuação.

É preciso alinhar sua trajetória a essa recuperação contemporânea e propositadamente anti-cartesiana (em alguns sentidos até mesmo anti-marxista e libertária) dos afetos.

Seu trabalho e seu olhar buscaram não só a emergência de meios e relações entre sujeitos e objetos, como também o foco na superação da dialética ruim, do mau infinito e da má consciência inerentes aos labirintos da subjetividade técnica ou apenas instrumental.

A opção é aproximar-se de autores atentos à etnografia interna dos objetos técnicos em sua relação com a individuação e a transindividuação - caso de Shelley Turkle. A obra de Turkle aponta claramente para uma etnografia da afetividade técnica que remonta ao mesmo Start Trek do holodeck de Janet Murray, em sua obra e de modo ainda mais radical em sua autobiografia, em que Turkle projeta sobre nossa relação com os objetos técnicos e com as máquinas semióticas o olhar afetivo da "empatia”, que ela mesma reconhece estar enraizada no episódio Empath da série. A tripulação da Enterprise entra em contato com um ser extraterrestre feminino que possui o dom de sentir e absorver a dor dos outros como "técnica" de ressuscitação (TURKLE, 2021, p. XIX).

Arlindo Machado faz justiça a uma distinção espinosana que remonta aos princípios da ciência moderna segundo os quais é fundamental distinguir entre "machina" e "fábrica" e, assim, não surpreende que ele mesmo tenha voltado sua atenção ao olho, ao cérebro e à relação biopolítica entre corpo, mente e técnica.

Contra o cartesianismo, Espinosa apresenta como primeira verdade o "eu sou" sem qualquer referência ao Cogito, a "relação entre ser e pensar sendo estabelecida por uma proposição e sua demonstração e não por uma intuição... Espinosa não escreve Cogito ergo sum, mas sum cogitans. Sou pensando” (CHAUÍ, 1981, p. 65-66). 
Arlindo Machado (associado às contribuições de Merleau-Ponty) poderia ter escrito "sou olhando e, assim, somos pensando". O olhar lindo de Arlindo é um pensamento da imagem técnica que faz sentido apenas na dimensão da construção afetiva sempre coletiva e intimamente, organicamente vinculada à fabricação do imaginário e da liberdade, não apenas a uma alienante, repetitiva e industrial maquinação.

Seu olhar aponta para um movimento contemporâneo que vai além do audiovisual, da técnica e da subjetividade alienada para nos convidar a reconstruir, como jogadores que negociam posições e visões, uma humanidade afetivamente mais resolvida.

Essa nova disposição exige, afinal, que "levar a sério" signifique exatamente o oposto do que parece dizer. Levar a fotografia, a TV, o cinema e os games a sério exige a superação da disciplina tecnofílica, ou seja, o abandono da confiança de funcionário no resultado preciso e coisificante dos gadgets.

A reprodutibilidade técnica da obra de arte não a condena (ou ao processo artístico e audiovisual) a uma perda inconsolável de um suposto paraíso da autenticidade, desde que adotemos uma perspectiva mediada pela diversidade e pelo questionamento biopolítico, e que abram-se as caixas pretas para novos momentos ou poderes auráticos (JANSEN, 2018) capazes de contribuir para a democratização por meio da criatividade de um jogador-artista que entra num jogo ou videogame como quem leva a vida real a sério.

A aproximação entre jogos e, de modo geral, vida lúdica digital, arte, narrativa e uma desalienação da tecnologia jamais perderá o potencial aurático que emerge a cada improvisação, a cada jogada, a cada representação ou performance ao vivo, em que nenhuma base de dados abolirá o acaso, a liberdade, a imaginação, a crítica e a criatividade como exercícios da própria ludicidade levada a sério.

\section{Referências}

$13^{a}$ BIENAL DE SÃO PAULO, Fundação Bienal de São Paulo, 2001. Disponível em: https://bit.ly/3cOLGGP. Acesso em: 16 jun. 2021.

BRITTON, S., COLLINS, D. (ed.). The eighth day: the transgenic art of Eduardo Kac. Tempe: Arizona State University, 2003.

CHAUÍ, M. Da realidade sem mistérios ao mistério do mundo: Espinosa, Voltaire, Merleau-Ponty. São Paulo: Brasiliense, 1981. 
CHAUÍ, M. Espinosa: ontogênese do singular e vida ética. doispontos, Curitiba/São Carlos, v. 16, n. 3, 2019. Disponível em: https://bit.ly/3gl4dww. Acesso em: 3 mar. 2021.

FASSLER, M. Ohne Spiegel leben, Sichtbarkeiten und posthumane Menschenbilder. Berlim: Fink (Wilhelm), 2000.

FEITOSA, S.A. "O Sujeito na Tela: modos de enunciação no cinema e no ciberespaço”. Intexto, Porto Alegre, v. 1, n. 18, p. 1-4, 2008.

GOMES, R. Agentes Verossímeis: uma investigação sobre a construção dos personagens autônomos nos videogames. Tese (Doutorado) - Pontifícia Universidade Católica, São Paulo, 2008. Disponível em: https://bit.ly/3xk6opR. Acesso em: 29 jun. 2021.

JANSEN, G. O poder aurático da recíproca multiplicação na América do Sul e na Europa. In: JANSEN, G. (Curador). O poder da multiplicação. Porto Alegre: Instituto Goethe, 2018. Disponível em: https://bit.ly/3xo6i0i. Acesso em: 8 mai. 2021.

LAUREL, B. Computers as Theatre. Boston: Addison-Wesley, 1991.

MACHADO, A. “Arte e Mídia: aproximações e distinções”. Galáxia, São Paulo, n. 4, p. 19-32, 2002a.

MACHADO, A. A visão sob enfoque audiovisual, policromias. Revista de Estudos do Discurso, Imagem e Som, Rio de Janeiro, v. 4, n. 2, 2019. Disponível em: https://bit. ly/3cETfzZ. Acesso em: 3 mar. 2021.

MACHADO, A. Novos Territórios do Documentário. Doc On-Line: Revista Digital de Cinema Documentário, n. 11, p. 5-24, 2011. Disponível em: https://bit.ly/2RTAEZD. Acesso em: 3 mar. 2021.

MACHADO, A. O Sujeito no ciberespaço. In: CONGRESSO BRASILEIRO DE COMUNICAÇÃO, 24., 2001, Campo Grande. Anais [...]. Campo Grande: Intercom, 2001. Disponível em: https://bit.ly/35kGAy0. Acesso em: 3 mar. 2021.

MACHADO, A. Regimes de imersão e modos de agenciamento. In: CONGRESSO BRASILEIRO DE CIÊNCIAS DA COMUNICAÇÃO, 25., 2002b, Salvador. Anais [...]. Salvador: Intrercom, 2002b. Disponível em: https://bit.ly/3vp92JJ. Acesso em: 8 mai. 2021.

MACHADO, A. "Repensando Flusser e as imagens técnicas". In: GIANNETTI, C. (org.). Arte en la era electrónica: perspectivas de una nueva estética. Barcelona: Centre de Cultura Contemporania de Barcelona, 1997a. Disponível em: https://bit. ly/3iT3nZV. Acesso em: 3 mar. 2021.

MACHADO, A. Um microchip dentro do corpo. Ekac, 1997b. Disponível em: http:// www.ekac.org/machado.html. Acesso em: 3 mar. 2021. 
MORAN, P., PATROCÍNIO, J. (org.). “Machinima”. CINUSP, São Paulo, v. 2, 2011. Disponível em: https://bit.ly/3zpi9gt. Acesso em: 3 mar. 2021.

MURRAY, J. H. Hamlet on the holodeck: the future of narrative in cyberspace. New York: Free Press, 1997.

TURKLE, S. The Empathy Diaries. London: Penguin, 2021.

\section{Referências audiovisuais}

ARLINDO Machado, tv e games (feat @ renatagames) \#10. Renata Gomes (realizadora). Brasil: Podcast Dazumana, Radiotube, 2020. Disponível em: https:// www.radiotube.org.br/audio-7684TvSSJpOO7. Acesso em: 2 mar. 2021.

submetido em: 5 mar. 2021| aprovado em: 6 maio 2021 